\title{
RED-TAILED HAWKS FLEDGE YOUNG FROM ARTIFICIAL NEST BOX
}

LORNE SCOTT, Box 995, Indian Head, Saskatchewan SOG 2K0

Eleven years ago I began setting out wooden nest box structures with the objective of enticing Great Horned Owls to nest in them. In 1969, I was thrilled to discover a pair of Red-tailed Hawks occupying the first box that I had set out.'

Being young and inexperienced, I climbed up to the nest box to discover the Red-tails were in the process of nest building. They deserted the nest and I regretfully learned that Redtailed and Swainson's Hawks will readily abandon their nests if people climb up to them during the construction or incubation period.

Red-tailed Hawks were not observed at any nest boxes during the next eight years. I had pretty well given up any hope of again finding Red-tails using one of the nest boxes, especially in view of the fact that their numbers have continued to decline during the 1970's in the Indian Head area.

During the evening of May 26, 1978, while cultivating summerfallow around an aspen bluff, I casually glanced up at a previously empty box in a poplar tree. To my utter surprise, the distinct outline of a hawk's head could be seen above the edge of the box. Because it was late in the evening, I made no attempt to stop and identify the hawk.

The next day while working near the nest site the bird flushed from the nest and was identified as a Red-tailed Hawk.

By June 21 , a fledgling could be seen

Red-tailed Hawk in artificial nest box

Lorne Scott

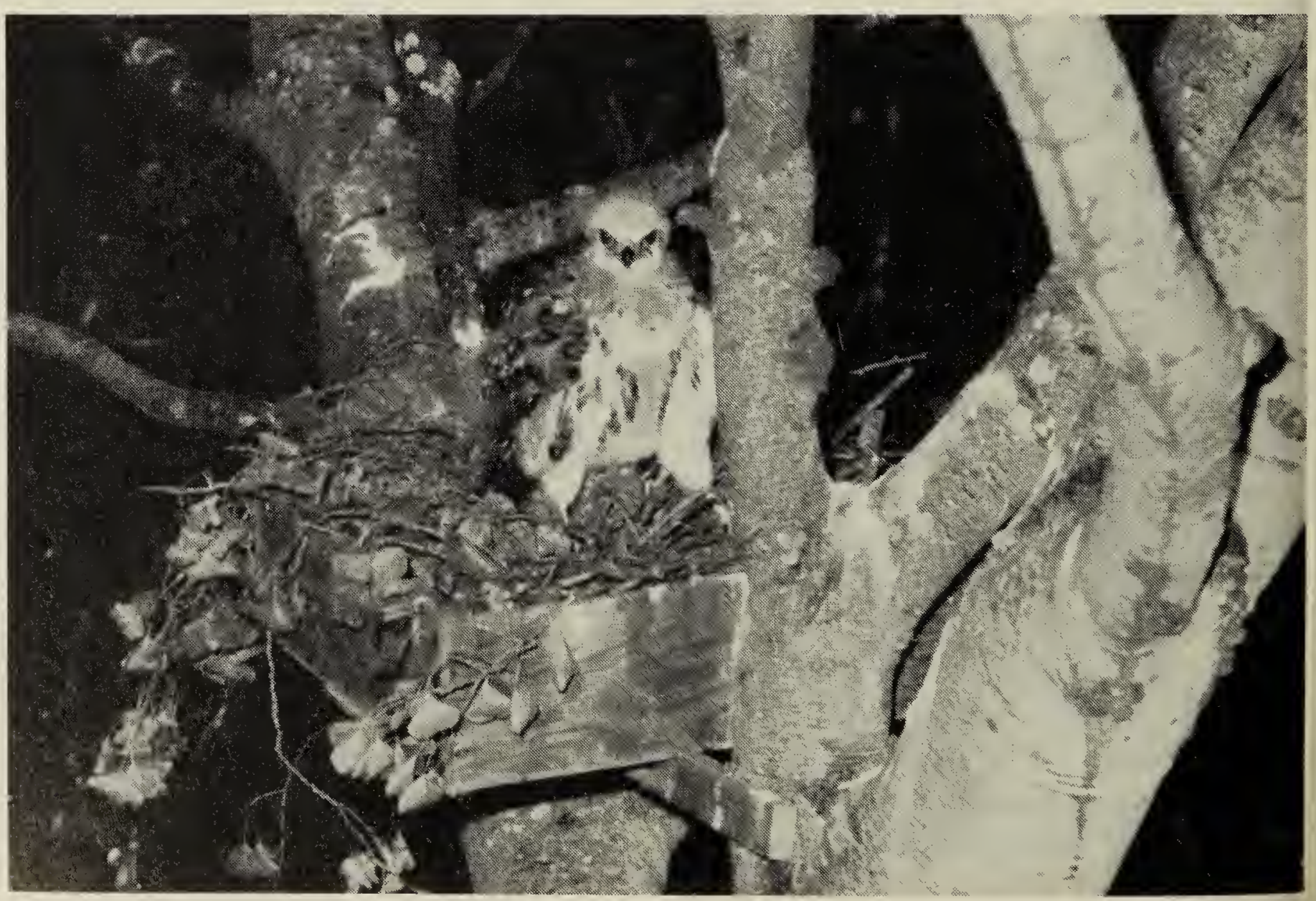




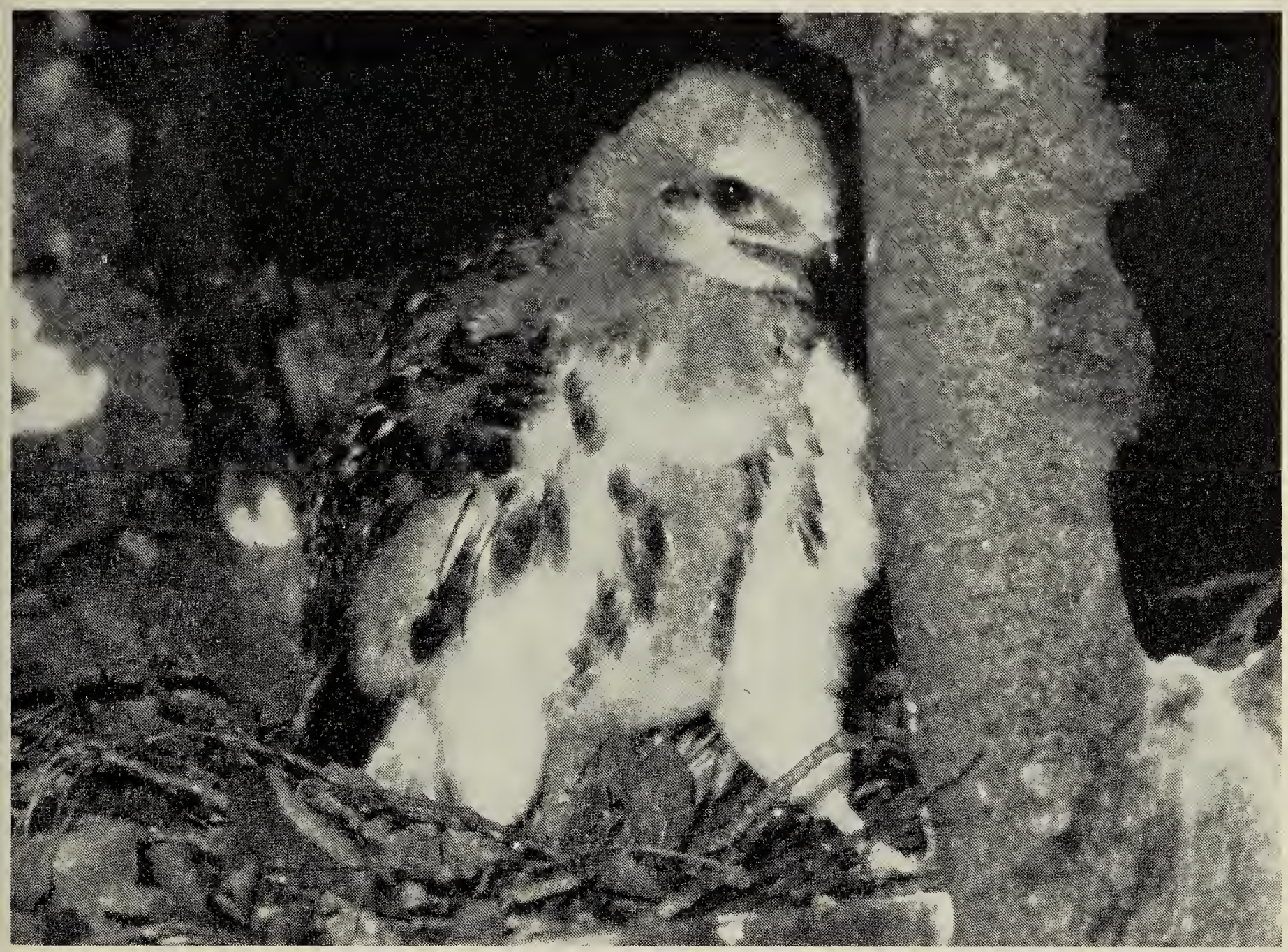

peering over the edge of the nest and, on June 28,1 climbed up to the nest and banded the single young and photographed it in the nest. The young Red-tail appeared to be between three and four weeks of age. Later in July it was observed flying in the area.

The nest box is made of plywood and is 20 inches square with sides five inches high. It is about 18 feet above the ground in a crotch between the trunk and a main branch of a large aspen poplar tree. Surrounding trees help to conceal the nest from the outer edge of the bluff.

Three years ago when 1 erected the nest box I placed dead twigs and dry bark in the box to prepare a nest for Great Horned Owls. The artificial site was not used until the Red-tails took up occupancy.

During their nesting activities the Red-tailed hawks brought many green apsen twigs with leaves to the box and placed them around the outer edge of the nest. On June 28, some of the twigs were old with dead leaves while others appeared fresh and recently brought to the nest.

In 1976 a pair of Red-tailed Hawks (perhaps the same pair as used the nest box) built a nest about 100 yards from the nest box. They did not fledge any young and were not observed in the area during 1977 . In the spring of 1977 , a pair of Great Horned Owls raised three young in the Red-tail's nest and in 1978, they again used the Red-tail's nest, raising two young.

In our part of southeast Saskatchewan Great Horned Owls are very dependent on old Red-tailed Hawk nests as nesting sites. The close proximity at which the two species nest would indicate that they are quite compatible.

'SCOTT, L. 1970. Great horned owls occupy artificial nesting site. Blue Jay 28(3):123 